\title{
Hemodynamic analysis of a novel bioresorbable scaffold in porcine coronary artery model
}

Erhan Tenekecioglu ${ }^{1} \mathrm{MD}$, Ryo Torii ${ }^{2} \mathrm{PhD}$, Christos V. Bourantas ${ }^{3} \mathrm{MD}, \mathrm{PhD}$, Rafael Cavalcante ${ }^{1} \mathrm{MD}, \mathrm{PhD}$, Yohei Sotomi ${ }^{4}$ MD, Yaping Zeng ${ }^{1}$ MD, PhD, Carlos Collet ${ }^{4} \mathrm{MD}$, Tom Crake ${ }^{3} \mathrm{MD}$, Alexandre Abizaid ${ }^{5} \mathrm{MD}, \mathrm{PhD}$, Yoshinobu Onuma ${ }^{1} \mathrm{MD}$, PhD, Solomon Su ${ }^{6} \mathrm{PhD}$, Teguh Santoso ${ }^{7} \mathrm{MD}$, PhD, Patrick W. Serruys MD, PhD ${ }^{1,8 *}$

1 Department of Interventional Cardiology, Erasmus University Medical Center, Thoraxcenter, Rotterdam, The Netherlands

2 Department of Mechanical Engineering, University College London, London, United Kingdom

3 Department of Cardiology, University College of London Hospitals, London, United Kingdom

4 Department of Cardiology, Academic Medical Center, University of Amsterdam, Amsterdam, The Netherlands

5 Department of Invasive Cardiology, Institute Dante Pazzanese of Cardiology, São Paulo, Brazil

6 DuNing Incorporated, Tustin, California

7 Department of Internal Medicine, Faculty of Medicine, Dr. Cipto Mangunkusumo and Medistra Hospitals, University of Indonesia, Jakarta, Indonesia

8 Department of Cardiology, International Centre for Circulatory Health, Imperial College, London, United Kingdom

* Corresponding author: patrick.w.j.c.serruys@gmail.com

\section{ABSTRACT}

Background The shear stress distribution assessment can provide useful insights for the hemodynamic performance of the implanted stent/scaffold. Our aim was to investigate the effect of a novel bioresorbable scaffold, Mirage on local hemodynamics in animal models.

Method The main epicardial coronary arteries of 7 healthy mini-pigs were implanted with 11 Mirage Microfiber sirolimus-eluting Bioresorbable Scaffolds (MMSES). Optical coherence tomography (OCT) was performed post scaffold implantation and the obtained images were fused with angiographic data to reconstruct the coronary artery anatomy. Blood flow simulation was performed and Endothelial Shear Stress (ESS) distribution was estimated for each of the 11 scaffolds. ESS data were extracted in each circumferential 5-degree subunit of each cross-section in the scaffolded segment. The generalized linear mixed-effect analysis was implemented for the comparison of ESS in two scaffold groups; $150-\mu \mathrm{m}$ strut thickness MMSES and $125-\mu \mathrm{m}$ strut thickness MMSES.

Results ESS was significantly higher in MMSES $(150 \mu \mathrm{m})$ [0.85(0.49-1.40) Pa], compared to MMSES (125 $\mu \mathrm{m})$ [0.68(0.35-1.18) Pa]. Both MMSES $(150 \mu \mathrm{m})$ and MMSES $(125 \mu \mathrm{m})$ revealed low recirculation zone percentages per luminal surface area $[3.17 \% \pm 1.97 \%$ in MMSES $(150 \mu \mathrm{m}), 2.71 \% \pm 1.32 \%$ in MMSES (125 $\mu \mathrm{m})]$.

Conclusion Thinner strut Mirage scaffolds induced lower shear stress due to the small size vessels treated as compared to the thick strut version of the Mirage which was implanted in relatively bigger size vessels. Vessel size should be taken into account in planning BRS implantation. Small vessels may not get benefit from BRS implantation even with a streamlined strut profile. This pilot study warrants comparative assessment with commercially available bioresorbable scaffolds. 


\section{INTRODUCTION}

Metallic drug eluting stents have significant limitations including the risks of neoatherosclerosis, late stent thrombosis, and restenosis which affect long term prognosis. Bioresorbable scaffolds (BRS) have been introduced to overcome these issues with potential benefits of allowing future treatments, non-invasive imaging procedures and recovering vessel physiology during bioresorption process of the scaffold. Despite its theoretical benefits, recent reports of neoatherosclerosis and scaffold thrombosis have emerged concerns about the designs of BRS [1]. Thicker struts, bulky structure, non-streamlined strut geometry and early mechanical disruption have been charged for underlying pathological mechanisms. Local coronary hemodynamics, particularly endothelial shear stress (ESS) seems to drive these mechanisms [2]. Following stent/scaffold implantation, the device geometry, strut profile, and curvature status of the implanted vessel segment influence the rheological behavior of the scaffolded segment [3]. The in vivo evaluation of the impact of protruding struts on local hemodynamic patterns in the current available BRS has revealed the interaction between shifted ESS and the intimal tissue response [4].

Mirage microfiber sirolimus-eluting bioresorbable scaffold (MMSES, Manli Cardiology, Singapore) is a novel coronary stent that has substantial differences in geometrical design, strut profile, strut thickness, and strut connector alignments. The objective of this preclinical study was to determine the flow characteristics and ESS distribution in MMSES implanted coronary artery segments.

\section{METHODS}

We analyzed data from Yucatan mini-pigs implanted with MMSES. Seven mini-pigs with healthy coronaries underwent percutaneous coronary intervention $(\mathrm{PCI})$ in select epicardial coronary arteries via the femoral access according to standard procedures. Six coronaries were implanted with a single MMSES with 150- $\mu \mathrm{m}$ strut thickness [MMSES $(150 \mu \mathrm{m})$ ] and five coronaries with a MMSES with $125-\mu \mathrm{m}$ strut thickness [MMSES $(125 \mu \mathrm{m})]$. The treated coronary arteries were imaged by OCT immediately after the scaffold implantation. The protocol approval for the animal study was received from the Institutional Animal Care and Use Committee and the study was conducted in accordance to the American Heart Association guidelines for preclinical research and the Guide for the Care and Use of Laboratory Animals [5].

\subsection{Scaffold design}

Mirage scaffold is produced from poly-d-I-lactide (PDLLA) of which d(dextro-rotary)-isomer constitutes $<5 \%$ of the total polylactic acid (PLA), coated with a biodegradable PLA eluting sirolimus. MMSES is manufactured by winding the polylactide monofilaments into helix-coiled structure. The struts have circular profile with thickness of $125 \mu \mathrm{m}$ in scaffolds with diameter $\leq 3 \mathrm{~mm}$, and $150 \mu \mathrm{m}$ in scaffolds with diameter $\geq 3.5 \mathrm{~mm}$ (Figure 1). The scaffold design consists of a helicoidal coil structure in which the monofilament maintains its directional mechanical properties as well as its circular geometry (Figure $2 \mathrm{~A}$ ). When compared to the benchmark Absorb scaffold (27\%), Mirage scaffold has $45 \%$ vessel luminal coverage ratio [6]. The helical-coil design is fastened by longitudinal spine microfibers providing radial strength for the MMSES $(150 \mu \mathrm{m})$ (148.54 kPa) and MMSES (125 $\mu \mathrm{m})(120.54 \mathrm{kPa})$ comparable to the current available BRS [7]. MMSES (125 $\mu \mathrm{m})$ and MMSES $(150 \mu \mathrm{m})$ have a tensile strength of $300 \mathrm{MPa}$ with an elongation at break of $35 \%$ (information from the manufacturer). In addition, in vitro and in vivo degradation profile has confirmed that the Mirage polylactide is basically fully biodegraded after 14 months (Figure 2B). 


\subsection{Data acquisition}

X-ray angiography was performed using Siemens HiCor cardiac angiography system (Siemens, Erlangen, Germany). OCT was performed following scaffold implantation in all the coronary arteries implanted with bioresorbable scaffolds. The treated segments were studied using a frequency-domain OCT system (C8-XR OCT Intravascular Imaging System; St. Jude Medical, St. Paul, MN) that was pulled-back at a speed of $18 \mathrm{~mm}$ sec-1. A nonocclusive flushing technique was used for blood clearance by injection of contrast media. The acquired data were stored in DICOM format and transferred to a workstation for further analysis.

\section{$\underline{2.3 \text { Coronary artery reconstruction }}$}

Coronary artery reconstruction was performed using a well-established and validated methodology [8]. In brief the angiographic and OCT data were reviewed to identify the scaffolded segment and the most proximal and distal anatomical landmarks (i.e. side branches) to the scaffolded segment, that were visible in both coronary angiography and OCT. These landmarks were used to define the segment of interest, that was reconstructed from OCT and X-ray angiographic data for computational fluid dynamic (CFD) model [8].

In the segment of interest, an observer identified the OCT images portraying the scaffolded and the native coronary artery and analyzed the OCT frames at every $0.1 \mathrm{~mm}$ interval in the scaffolded segment and at every $0.2 \mathrm{~mm}$ interval in the native vessel. In the native and the scaffolded segment the observer delineated the flow area-defined in the native segment by the lumen border and in the scaffolded segment by the adluminal side of the struts and by the lumen surface in the areas between the struts [9].

Two post-procedure end-diastolic X-ray angiographic images with at least $>30^{\circ}$ angle difference portraying the segment of interest with minimal foreshortening were selected with the table in the isocenter. In these images the lumen borders were detected for the segment of interest and used to extract the luminal centerline that was then used to define the 3D luminal centerline of the segment of interest [8]. The borders detected in the OCT images were then placed perpendicularly onto the luminal centerline and anatomical landmarks, that were side-branches seen in both OCT and X-ray images were used to define the absolute orientation of the OCT frames [8].

\section{$\underline{2.4 \text { Blood flow simulation }}$}

The reconstructed images were processed with CFD techniques. A finite volume mesh was generated and then blood flow simulation was performed and the ESS was estimated by solving the 3D Navier-Stokes equations (ANSYS Fluent, Canonsburg, Pennsylvania) [10]. To assess the effect of the scaffold designs on the local hemodynamic micro-environment, the mesh density around the scaffold struts and within the boundary layer of the flow field between the struts was increased to have an average element edge of 30 $\mu \mathrm{m}$ (equal to $1 / 4$ of the strut thickness of the scaffold strut). Blood was assumed to be a homogeneous, Newtonian fluid with a viscosity of $0.0035 \mathrm{~Pa} \mathrm{~s}^{-1}$ and a density of $1,050 \mathrm{~kg} \mathrm{~m}^{-3}$. A steady flow profile was simulated at the inflow of the 3D models. Previously, publications showed that there are no significant differences between the ESS estimated in pulsatile and steady flow simulations [11, 12]. Blood flow for each reconstruction was estimated by measuring, in the two angiographic projections, the number of frames required for the contrast agent to pass from the inlet to the outlet of the reconstructed segment, the volume of the reconstructed segment and the cine frame rate $[2,13]$. The arterial wall was considered to be rigid. No-slip conditions were imposed at the scaffold surface. At the outlet of the model zero pressure conditions were imposed. ESS at the baseline luminal surface was calculated as the product of blood viscosity and the gradient of blood velocity at the wall [14]. The ESS was measured in the native and the scaffolded segment 
around the circumference of the lumen per $5^{\circ}$ interval (sector) and along the axial direction per $0.2-\mathrm{mm}$ interval with the use of an in-house algorithm [4] (Figure 3). The recirculation zones in the vicinity of the struts were quantified based on the direction of the ESS vector and the centerline vector. Areas where the ESS vector had opposite direction to the centerline vector were considered to be exposed to recirculation zones (Figure 4).

\section{$\underline{2.5 \text { Statistical analysis }}$}

Continuous variables were tested for normality with Kolmogorov-Smirnov test and are presented as mean \pm SD or median (interquartile range) as appropriate. Categorical variables are presented as counts and percentages. Mixed linear model with an assumed Gaussian distribution was used for the comparisons of continuous variables to take into account the clustered nature of $>1$ scaffolds analyzed from the same animals and $>1$ cross-sections from the same scaffold and $>15^{\circ}$-sectors from the same cross-sections, that should be in correlations within the clusters. Pearson correlation coefficients were used to evaluate the strength and direction of the linear relationship between the strut thickness, cross-section area and ESS. Statistical significance was assumed at a probability $(\mathrm{P})$ value of $<0.05$. All statistical analyses were performed with SPSS (version 22.0.0, IBM, New York).

\section{RESULTS}

In MMSES $(150 \mu \mathrm{m})$ group ( $n=6$ arteries), 2 LAD, 1 LCX and 3 RCA, in MMSES (125 $\mu \mathrm{m})$ group ( $n=5$ arteries) 2 LAD, 1 LCX and 2 RCA were treated. The list of scaffolds with diameters, lengths, deployment pressures, post-implantation dilatation balloon pressures, post-implantation scaffolded vessel segment diameters and the treated coronaries with the implantation locations are shown in Table 1. The dimensions of the proximal segment, scaffolded segment and the distal segment are shown in Table 2 and Supporting Information Table 1.

The median ESS of MMSES $(150 \mu \mathrm{m})$ and MMSES $(125 \mu \mathrm{m})$ are 0.85 (IQ:0.49-1.39) and 0.68 (IQ:0.35-1.18), respectively. The histograms of ESS for the MMSES $(150 \mu \mathrm{m})$ and MMSES $(125 \mu \mathrm{m})$ (Figure 5) show that, $58 \%$ of the scaffolded vessel luminal surface in the MMSES $(150 \mu \mathrm{m})$ and 66\% MMSES $(125 \mu \mathrm{m})$ was exposed to a low (<1 Pa) athero-promoting ESS environment (Figure 6) (Table 3). This paradoxical results should stem from the fact that the MMSES $(125 \mu \mathrm{m})$ was implanted in small size $(<3.0 \mathrm{~mm})$ vessels while the MMSES (150 $\mu \mathrm{m})$ was implanted in bigger size $(>3.5 \mathrm{~mm})$ vessels; when the strut thickness was divided to final lumen diameter after the implantation the mean ratio in MMSES $(125 \mu \mathrm{m})$ was 0.020 and in MMSES $(150 \mu \mathrm{m})$ was 0.017 . The percentages of recirculation area per scaffolded vessel segment surface area were $3.17 \% \pm 1.97 \%$ in MMSES $(150 \mu \mathrm{m})$ and $2.71 \% \pm 1.32 \%$ in MMSES $(125 \mu \mathrm{m})$. At device level, there was no statistical difference between the scaffold groups for recirculation area $(P=0.91)$ (Table 4). ESS had a negative correlation with strut thickness $(r=-0.17, P<0.0001)$. The strut thickness had significant correlation with the recirculation zone area per luminal surface area $(r=0.555, P<0.0001)$.

\section{DISCUSSION}

In this exploratory study, we evaluated Mirage scaffold with two strut thicknesses in porcine coronary artery models. The findings were as follows: (1) The thinner strut version Mirage scaffold [MMSES (125 $\mu \mathrm{m})$ ] was implanted in smaller vessels $(<3.0 \mathrm{~mm})$ while thick strut version Mirage [MMSES $(150 \mu \mathrm{m})]$ was implanted in bigger size $(>3.5 \mathrm{~mm})$ vessels which induced lower ESS in MMSES $(125 \mu \mathrm{m})$ than in MMSES $(150 \mu \mathrm{m})$ and due 
to the same fact, (2) The percent luminal surface exposed to lower-ESS (<1.0 Pa) was higher in MMSES (125 $\mu \mathrm{m})$ as compared to MMSES $(150 \mu \mathrm{m})$. (3) Scaffolded segments revealed minimal recirculation zones per scaffolded luminal surface. However, due to device level comparison, there was no significant difference for recirculation area percentages between MMSES $(150 \mu \mathrm{m})$ and MMSES $(125 \mu \mathrm{m})$ underscoring the role that the artery size plays in the regional hemodynamic effects of the scaffold placement.

Several in silico studies have mentioned the effect of stent design on local hemodynamics after device implantation. Mirage scaffold has a unique helicoidal design with thinner strut thicknesses. The circular strut profile gives an advantage to Mirage scaffold inducing potentially less flow disruption [3]. The streamlined strut profile exhibited minimal recirculation areas and less shifted ESS distributions in this novel scaffold [15]. The helicoidal design provides less flow disruption and recirculation areas compared to the corrugated ring design $[15,16]$. Mirage scaffold has $45 \%$ vessel luminal coverage ratio which can also help to explain low percentage of recirculation areas per luminal surface in scaffolded segments. The high coverage ratio with streamlined strut profile should have enabled the flow streamlines be in an aligned structure within the scaffolded segments. The increased luminal surface coverage decreases the risk of the interaction between disrupted flow and denuded endothelial layer that prevents the activation of pathological cellular mechanisms for tissue response and thrombus formation. In Mirage scaffold, the maximal coil pitch between the helicoidal rings is $0.8 \mathrm{~mm}$ which is enough for an inter-strut space to recover a smooth flow after disruption in the vicinity of the struts $[17,18]$. Helicoidal design, thinner circular strut, increased luminal surface coverage and an adequate maximal coil pitch are the contributing factors for relatively low flow disruption in the scaffolded vessel segments [15]. In vitro experimental studies have demonstrated that the different strut designs have different influences on the local flow behavior. Strut thickness, strut shape and material properties have impact on the local flow. While strut thickness increases, the flow disruption around the strut increases [19]. Not only the strut thickness, but also the strut cross-profile has impact on flow disruption. The effect of strut thickness on the flow disruption in streamlined and non-streamlined strut profiles is not the same; as the thickness increases in a non-streamlined strut design, the flow disturbance demonstrates a nonlinear increment. Regarding the increase in flow disruption, experiments have demonstrated a rise in the fibrin accumulation around the struts. In the same line with these experimental studies, we have reported the effect of square-shaped struts on the local flow dynamics using similar porcine model and similar methodology for the flow simulation and shear stress analysis. In our previous study [15, 20], in Absorb implanted segments median shear stress level was 0.57 ([IQR]: 0.29-0.99) Pa. In Absorb implanted segments, $75 \%$ of the scaffolded surface was exposed to a low $(<1 \mathrm{~Pa})$ athero-promoting ESS and the percentage of recirculation area was $3.26 \% \pm 2.07 \%$. Using similar animal model and CFD methodology, in the present study, median ESS of MMSES $(150 \mu \mathrm{m})$ and MMSES $(125 \mu \mathrm{m})$ were $0.85(I Q: 0.49-1.39) \mathrm{Pa}$ and 0.68 (IQ:0.35-1.18) Pa which were quite higher than Absorb in our previous study [15]. Regarding low ESS, $58 \%$ of the scaffolded vessel luminal surface in MMSES $(150 \mu \mathrm{m})$ and 66\% in MMSES $(125 \mu \mathrm{m})$ were exposed to low ( $<1 \mathrm{~Pa}$ ) ESS those were quite lower than in Absorb (75\%). The percentages of recirculation area per scaffolded vessel surface area were $3.17 \% \pm 1.97 \%$ in MMSES $(150 \mu \mathrm{m})$ and $2.71 \% \pm 1.32 \%$ in MMSES $(125$ $\mu \mathrm{m})$ which were lower than in Absorb $(3.26 \% \pm 2.07 \%)$.

In many experimental CFD analyses, thinner streamlined struts were in favor of flow hemodynamics, inducing less flow separation and less recirculation zones in the vicinity of the struts (3). In our exploratory study, the ESS values were paradoxically lower in MMSES $(125 \mu \mathrm{m})$ than in MMSES $(150 \mu \mathrm{m})$. The main factor to explain this paradoxical result is the fact that as realized in Table 2 the final diameter of the vessels in Mirage $(150 \mu \mathrm{m})$ was higher (mean $3.75 \mathrm{~mm}$ ) than in Mirage $(125 \mu \mathrm{m})$ (mean $3.04 \mathrm{~mm}$ ) following the implantation. When the strut thickness is divided to the final luminal diameters in scaffolded vessel segments after implantation, it will be realized that the ratio of strut thickness/final lumen size is lower (strut thickness/final lumen diameter $=0.017)$ in Mirage $(150 \mu \mathrm{m})$ than in Mirage $(125 \mu \mathrm{m})$ (strut thickness/final lumen diameter $=0.020)$. It's obvious that the scaffolds with thinner struts [Mirage $(125 \mu \mathrm{m})$ ] were 
implanted in smaller vessels $(<3.0 \mathrm{~mm})$ whereas thick strut version of Mirage [Mirage $(150 \mu \mathrm{m})$ ] was implanted in bigger size vessels $(>3.5 \mathrm{~mm})$. However, in smaller vessels, even thinner struts induced lower ESS which denotes the fact that in small vessels the deteriorating effect of the struts are not avoidable despite thinner design. It seems that even with thin strut thicknesses, the small vessels may not benefit from BRS implantation. Because of this point, in correlation with mean ESS values, we found lower surface area exposed to $<1 \mathrm{~Pa}$ ESS in Mirage $(150 \mu \mathrm{m})$ rather than in Mirage $(125 \mu \mathrm{m})$. These results showed that during planning stage of the $\mathrm{PCl}$, scaffold strut thickness/vessel size diameter ratio should be taken into account to decrease fluctuations in ESS post-implantation. Another contributing factor for paradoxical result might be due to the Coanda effect; the flow is accelerating over the convex surfaces and in thicker circular struts this effect increases along with the elevated shear stress levels on the top surface of the struts [21]. As the thicker struts get in touch with the faster flowing flow zones in the radial direction within the vessel lumen, it results in higher shear stress levels at the top surface of the struts which also contributed higher levels of ESS in Mirage $(150 \mu \mathrm{m})$ compared to Mirage $(125 \mu \mathrm{m})$ (Supporting Information)."

\section{$\underline{4.1 \text { Limitations }}$}

The current results require interpretation within the constraints of some limitations. First, scaffold implantation was performed in healthy coronary arteries. Therefore, it was not possible to examine the implications of scaffold under-expansion or the composition of the underlying plaque on strut embedment which potentially influence the local flow hemodynamics. Second, there was no comparator which would enable to make a hypothesis for the "hemo-compatible" properties of Mirage bioresorbable scaffold.

\section{CONCLUSION}

Mirage scaffold has unique properties of helicoidal design, thinner struts-compared to current commercial available scaffolds-and streamlined strut profile. However, thinner strut version of Mirage induced lower ESS than thick strut version due to the higher ratio of strut thickness/lumen area in Mirage (125 $\mu \mathrm{m})$. The size of the target vessel segment should be assessed before the implantation of Mirage scaffold and small vessels should not be implanted with Mirage. The CFD study can be used to increase the hemo-compatibility of the bioresorbable scaffolds. The results should prompt further comparative study with the commercially available scaffolds in animal and human models.

\section{Disclosures}

E. Tenekecioglu has a research grant from TUBITAK (The Scientific Council of Turkey). P.W. Serruys is a member of the International Advisory Board of Abbott Vascular. Y. Onuma is a member of the International Advisory Board of Abbott Vascular. The preclinical study was implemented by TS and AA, the design and modification of the scaffold was conducted by SS and PWS, angiographic analyses were performed by YO, OCT analyses were performed by YS, manual contour notations in OCT for coronary artery reconstructions were performed by $\mathrm{ET}, 3 \mathrm{D}$ vessel reconstructions were done by $\mathrm{CB}$, blood flow simulations were implemented by RT, statistical analyses were performed by RC and TC, manuscript was drafted by ET and CC, manuscript was revised by PWS, first revision was done by ET, CC and YZ. Figures were prepared by ET and YZ. All the authors read and approved the last version of the text. 


\section{REFERENCES}

1. Mukete BN, van der Heijden LC, Tandjung K, et al. Safety and efficacy of everolimus-eluting bioresorbable vascular scaffolds versus durable polymer everolimus-eluting metallic stents assessed at 1-year follow-up: A systematic review and meta-analysis of studies. Int J Cardiol 2016;221:1087-1094.

2. Papafaklis MI, Bourantas CV, Theodorakis PE, et al. The effect of shear stress on neointimal response following sirolimus- and paclitaxel-eluting stent implantation compared with bare-metal stents in humans. JACC Cardiovasc Intervent 2010;3:1181-1189.

3. Jimenez JM, Davies PF. Hemodynamically driven stent strut design. Ann Biomed Eng 2009;37:14831494.

4. Bourantas CV, Papafaklis MI, Kotsia A, et al. Effect of the endothelial shear stress patterns on neointimal proliferation following drug-eluting bioresorbable vascular scaffold implantation: An optical coherence tomography study. JACC Cardiovasc Intervent 2014;7:315-324.

5. Clark JD, Gebhart GF, Gonder JC, Keeling ME, Kohn DF. The 1996 Guide for the Care and Use of Laboratory Animals. ILAR J 1997;38:41-48.

6. Tenekecioglu E, Torii R, Bourantas C, et al. Difference in hemodynamic microenvironment in vessels scaffolded with absorb BVS and mirage BRMS: Insights from a pre-clinical endothelial shear stress study. Eurolntervention. 2017 Jun 6. doi: 10.4244/EIJ-D-17-00283 [Epub ahead of print].

7. Ormiston JA, Webber B, Ubod B, Darremont O, Webster MW. An independent bench comparison of two bioresorbable drug-eluting coronary scaffolds (Absorb and DESolve) with a durable metallic drug-eluting stent (ML8/Xpedition). Eurolntervent J EuroPCR Collab Working Group Int Cardiolo Eur Soc Cardiol 2015;11:60-67.

8. Bourantas CV, Papafaklis MI, Lakkas L, et al. Fusion of optical coherence tomographic and angiographic data for more accurate evaluation of the endothelial shear stress patterns and neointimal distribution after bioresorbable scaffold implantation: Comparison with intravascular ultrasound-derived reconstructions. Int J Cardiovasc Imaging 2014;30:485-494.

9. Nakatani S, Sotomi Y, Ishibashi $Y$, et al. Comparative analysis method of permanent metallic stents (XIENCE) and bioresorbable poly-l-lactic (PLLA) scaffolds (Absorb) on optical coherence tomography at baseline and follow-up. Eurolntervent J EuroPCR Collab Working Group Int Cardiol Eur Soc Cardiol 2016;12:1498-1509.

10. Papafaklis MI, Bourantas CV, Theodorakis PE, Katsouras CS, Fotiadis DI, Michalis LK. Relationship of shear stress with in-stent restenosis: Bare metal stenting and the effect of brachytherapy. Int J Cardiol 2009;134:25-32. 
11. Feldman CL, llegbusi OJ, Hu Z, Nesto R, Waxman S, Stone PH. Determination of in vivo velocity and endothelial shear stress patterns with phasic flow in human coronary arteries: A methodology to predict progression of coronary atherosclerosis. Am Heart J 2002;143:931-939.

12. Tenekecioglu E, Torii R, Bourantas $C$, et al. Preclinical assessment of the endothelial shear stress in porcine-based models following implantation of two different bioresorbable scaffolds: Effect of scaffold design on the local haemodynamic micro-environment. Eurolntervent J EuroPCR Collab Working Group Intervent Cardiol Eur Soc Cardiol 2016;12:1296.

13. Sakamoto S, Takahashi S, Coskun AU, et al. Relation of distribution of coronary blood flow volume to coronary artery dominance. Am J Cardiol 2013;111:1420-1424.

14. Stone PH, Saito S, Takahashi S, et al. Prediction of progression of coronary artery disease and clinical outcomes using vascular profiling of endothelial shear stress and arterial plaque characteristics: The PREDICTION study. Circulation 2012;126:172-181.

15. Tenekecioglu E, Torii R, Bourantas C, et al. Assessment of the hemodynamic characteristics of Absorb BVS in a porcine coronary artery model. Int J Cardiol 2017;227:467-473.

16. Seo T, Schachter LG, Barakat Al. Computational study of fluid mechanical disturbance induced by endovascular stents. Ann Biomed Eng 2005;33:444-456.

17. Berry JL, Santamarina A, Moore JE Jr., Roychowdhury S, Routh WD. Experimental and computational flow evaluation of coronary stents. Ann Biomed Eng 2000;28:386-398.

18. Akagawa E, Ookawa K, Ohshima N. Endovascular stent configuration affects intraluminal flow dynamics and in vitro endothelialization. Biorheology 2004;41:665-680.

19. Jimenez JM, Prasad V, Yu MD, et al. Macro- and microscale variables regulate stent haemodynamics, fibrin deposition and thrombomodulin expression. J R Soc Interface 2014;11:20131079.

20. Tenekecioglu E, Torii R, Bourantas C, et al. Corrigendum to "assessment of the hemodynamic characteristics of absorb BVS in a porcine coronary artery model" [Int J Cardiol. 2017;227:467-473]. Int J Cardiol. 2017; 235:206.

21. Subhash M, Dumas A. Computational study of coanda adhesion over curved surface. SAE Int J Aerosp 2013;6:260-272. 
Table 1. Inventory of scaffolds with strut thicknesses and implantation parameters.

\begin{tabular}{|c|c|c|c|c|c|c|c|}
\hline Scaffold & Animal & Vessel & $\begin{array}{l}\text { Saffolded } \\
\text { vessel } \\
\text { segment }\end{array}$ & $\begin{array}{l}\text { Scaffold } \\
\text { size (mm) }\end{array}$ & $\begin{array}{l}\text { Deployment } \\
\text { balloon } \\
\text { pressure (atm) }\end{array}$ & $\begin{array}{l}\text { Post-dilatation } \\
\text { balloon } \\
\text { inflation } \\
\text { pressure (atm) }\end{array}$ & $\begin{array}{l}\text { The scaffolded } \\
\text { vessel segment } \\
\text { diameter after } \\
\text { implantation } \\
\text { (mm) }\end{array}$ \\
\hline $\begin{array}{c}\text { MMSES- } \\
1(125 \mu \mathrm{m})\end{array}$ & Animal-E & LCX & Mid & $2.75 \times 13$ & 6 & 16 & 3.0 \\
\hline $\begin{array}{c}\text { MMSES- } \\
2(125 \mu \mathrm{m})\end{array}$ & Animal-F & LAD & Prox & $2.75 \times 13$ & 16 & 18 & 3.0 \\
\hline $\begin{array}{c}\text { MMSES- } \\
3(150 \mu \mathrm{m})\end{array}$ & Animal-D & LCx & Mid & $3.50 \times 15$ & 6 & 14 & 3.7 \\
\hline $\begin{array}{c}\text { MMSES- } \\
4(150 \mu \mathrm{m})\end{array}$ & Animal-D & RCA & Mid & $3.50 \times 15$ & 6 & 16 & 3.7 \\
\hline $\begin{array}{c}\text { MMSES- } \\
5(125 \mu \mathrm{m})\end{array}$ & Animal-E & LAD & Mid & $2.50 \times 15$ & 6 & 16 & 2.6 \\
\hline $\begin{array}{c}\text { MMSES- } \\
6(150 \mu \mathrm{m})\end{array}$ & Animal-C & LAD & Prox & $3.50 \times 15$ & 6 & 16 & 3.7 \\
\hline $\begin{array}{c}\text { MMSES- } \\
7(150 \mu \mathrm{m})\end{array}$ & Animal-G & RCA & Mid & $3.50 \times 15$ & 6 & 14 & 3.3 \\
\hline $\begin{array}{c}\text { MMSES- } \\
8(125 \mu \mathrm{m})\end{array}$ & Animal-A & RCA & Mid & $3.00 \times 15$ & 12 & 20 & 3.8 \\
\hline $\begin{array}{c}\text { MMSES- } \\
9(125 \mu \mathrm{m})\end{array}$ & Animal-F & RCA & Mid & $3.00 \times 15$ & 10 & 18 & 18 \\
\hline $\begin{array}{c}\text { MMSES- } \\
10(150 \mu \mathrm{m})\end{array}$ & Animal-B & RCA & Mid & $3.50 \times 15$ & 18 & 16 & 3.8 \\
\hline $\begin{array}{c}\text { MMSES- } \\
11(150 \mu \mathrm{m})\end{array}$ & Animal-A & LAD & Prox & $3.50 \times 15$ & 16 & \\
\hline
\end{tabular}

Table 2. The OCT analyzes of scaffolded and non-scaffolded segments according to the scaffold type (device level)

\begin{tabular}{|l|l|l|}
\hline & MMSES $(\mathbf{1 5 0} \boldsymbol{\mu m})(\boldsymbol{n}=\mathbf{6})$ & MMSES (125 $\mu \mathrm{m})(\boldsymbol{n}=\mathbf{5})$ \\
\hline Scaffolded segment lumen area $\left(\mathrm{mm}^{2}\right)$ & $8.65(4.50-12.80)$ & $6.35(3.49-9.21)$ \\
\hline Distal non-scaffolded segment lumen area $\left(\mathrm{mm}^{2}\right)$ & $7.67(5.85-9.42)$ & $5.14(2.01-8.27)$ \\
\hline $\begin{array}{l}\text { Proximal non-scaffolded segment lumen area } \\
\left(\mathrm{mm}^{2}\right)\end{array}$ & $7.67(5.85-9.49)$ & $5.58(4.69-6.47)$ \\
\hline Strut area $\left(\mathrm{mm}^{2}\right)$ & $0.88(0.60-1.16)$ & $0.63(0.22-1.04)$ \\
\hline
\end{tabular}

The results are as Median (Quartile 1-Quartile 3). 
Table 3. The median ESS of the scaffold groups in $5^{\circ}$-sectorial subunit level.

\begin{tabular}{|c|c|c|}
\hline & $\begin{array}{l}\text { MMSES }(150 \mu)(n=31,176) \\
\text { Median }(Q 1-Q 3)\end{array}$ & $\begin{array}{l}\text { MMSES }(125 \mu)(n=22,248) \\
\text { Median }(Q 1-Q 3)\end{array}$ \\
\hline ESS [Pa] ( $5^{\circ}$-sectorial subunit level) & $0.85(0.49-1.39)$ & $0.68(0.35-1.18)^{*}$ \\
\hline $\mathrm{ESS} \leq 1.0 \mathrm{~Pa}(\%)$ & 57.7 & $66.4^{\#}$ \\
\hline
\end{tabular}

* Significant difference between MMSES $(150 \mu \mathrm{m})$ and MMSES $(125 \mu \mathrm{m}) ; \mathrm{P}<0.00001$.

\# Significant difference between MMSES $(150 \mu \mathrm{m})$ and MMSES $(125 \mu \mathrm{m}) ; \mathrm{P}<0.00001$.

$P$ values derived from a multilevel linear regression model that adjusted ESS values for vessel type and scaffold cross-sectional area, given the clustered nature of the data.

Table 4. Recirculation area per scaffolded vessel surface area percentages in scaffold groups.

\begin{tabular}{|l|c|c|}
\hline Scaffold & Recirculation area per scaffolded vessel surface area (\%) & Mean \pm SD \\
\hline MMSES-3 $(150 \mu \mathrm{m})$ & 5.81 & \\
\cline { 1 - 2 } MMSES-4 $(150 \mu \mathrm{m})$ & 1.35 & \multirow{3}{*}{$2.71 \pm 1.32^{*}$} \\
\hline MMSES-6 $(150 \mu \mathrm{m})$ & 1.60 & \\
\hline MMSES-7 $(150 \mu \mathrm{m})$ & 3.98 & \\
\hline MMSES-10 $(150 \mu \mathrm{m})$ & 1.40 & \\
\hline MMSES-11 $(150 \mu \mathrm{m})$ & 4.88 & \multirow{3}{*}{$3.17 \pm 1.97$} \\
\hline MMSES-1 $(125 \mu \mathrm{m})$ & 2.00 & \\
\hline MMSES-2 $(125 \mu \mathrm{m})$ & 2.81 & \\
\hline MMSES-5 $(125 \mu \mathrm{m})$ & 0.87 & \\
\hline MMSES-8 $(125 \mu \mathrm{m})$ & 3.93 & \\
\hline MMSES-9 $(125 \mu \mathrm{m})$ & 3.98 & \\
\hline
\end{tabular}

* Comparison between MMSES $(150 \mu \mathrm{m})$ and MMSES $(125 \mu \mathrm{m}), \mathrm{P}=0.91$

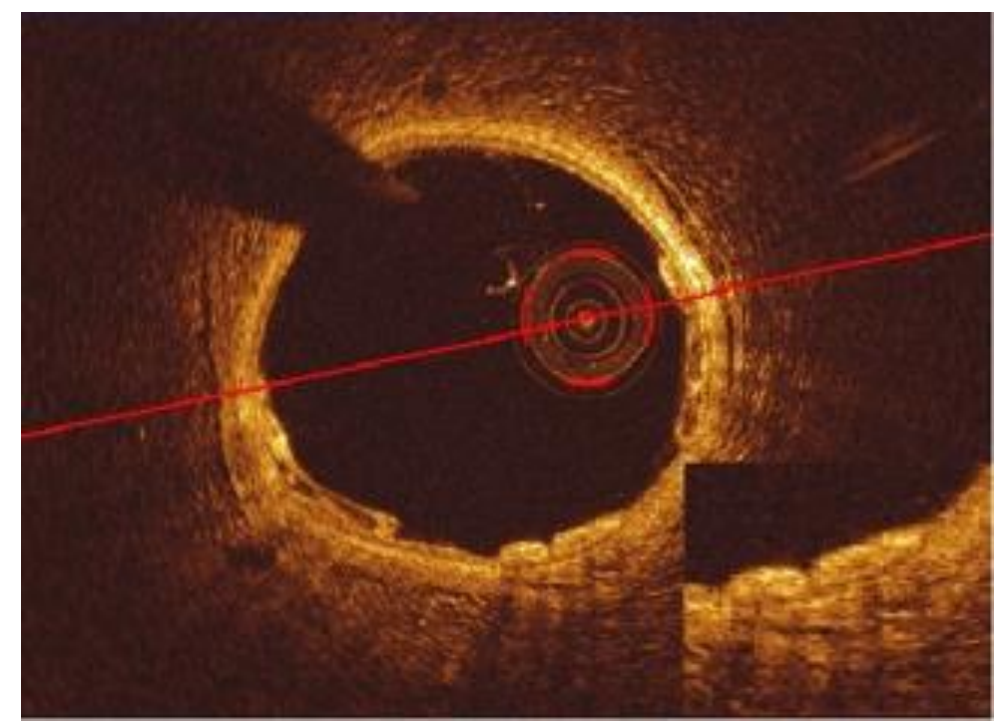

Figure 1. OCT cross-section image of Mirage scaffold. The strut of the Mirage scaffold is circular and nontranslucent. 


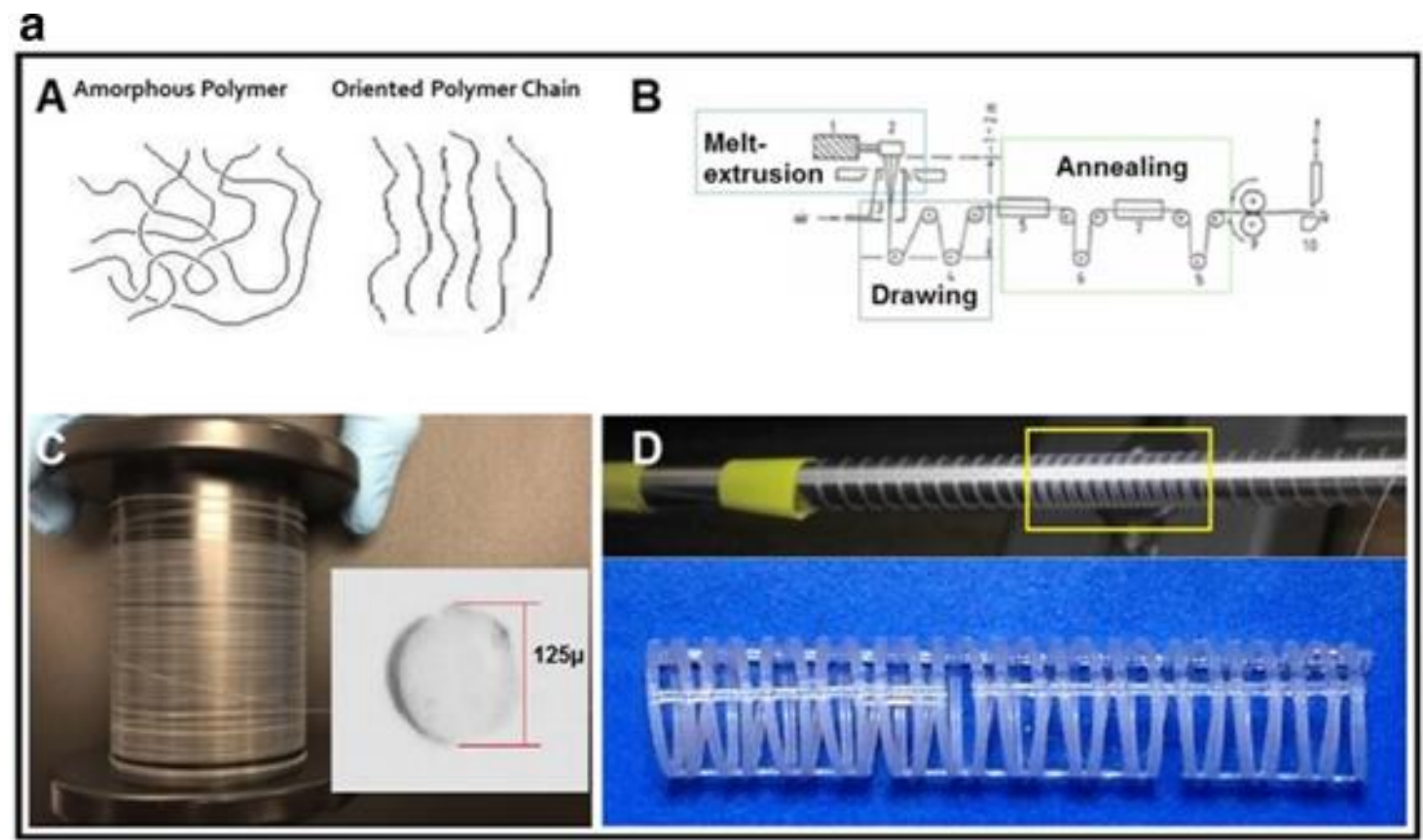

b

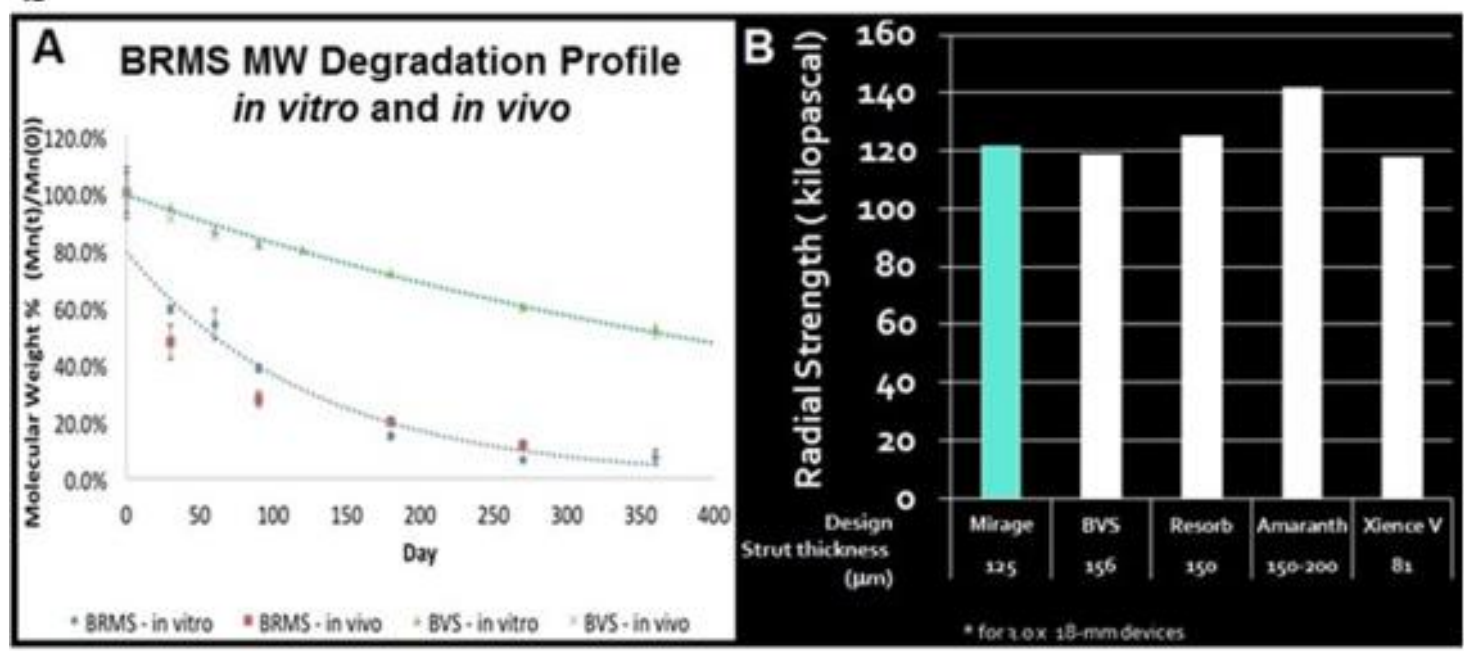

Figure 2. (A) Manli cardiology's microfiber technology. Highly oriented polylactide polymer is extruded and annealed to form a circular monofilament with preferred directional mechanical properties (A, B). Conversion of a circular monofilament into a helicoidal scaffold with circular strut geometry. Coil design enables scaffold to inherit monofilament's directional mechanical properties and monofilament's circular geometry (C, D). Three longitudinal spines are attached at ambient temperature to guarantee the mechanical stability of the helicoidal structures (D).(Produced with permission from JACC Int). (B) Mirage scaffold degradation and radial strength profile. In vitro and in vivo degradation profile in comparison with the BVS has confirmed that the Mirage polylactide is basically fully biodegraded after 14 months (A). Mirage scaffold with strut thickness of 125 micron has a tensile strength of $300 \mathrm{MPa}$ with an elongation at break of $35 \%$ and a radial strength of $120 \mathrm{kPa}$,-very comparable to the radial strength of the Xience $\mathrm{V}$ for a strut thickness of 81 micron (B). (Produced with permission from JACC Int) 


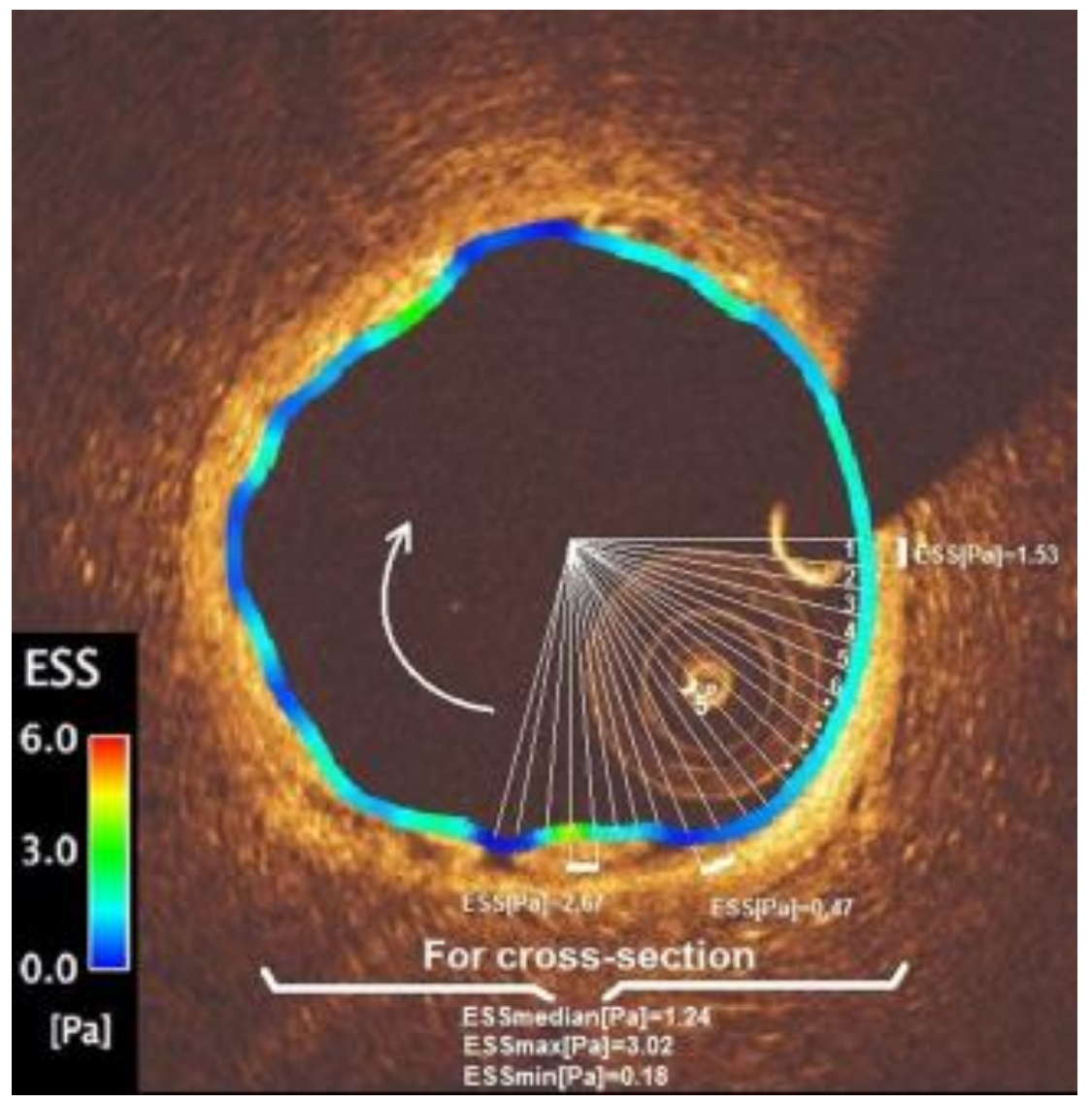

Figure 3. Circumferential ESS values (median, maximum and minimum) over the luminal perimeter at $5^{\circ}$ subunits (sectors) counted from 3 o'clock.

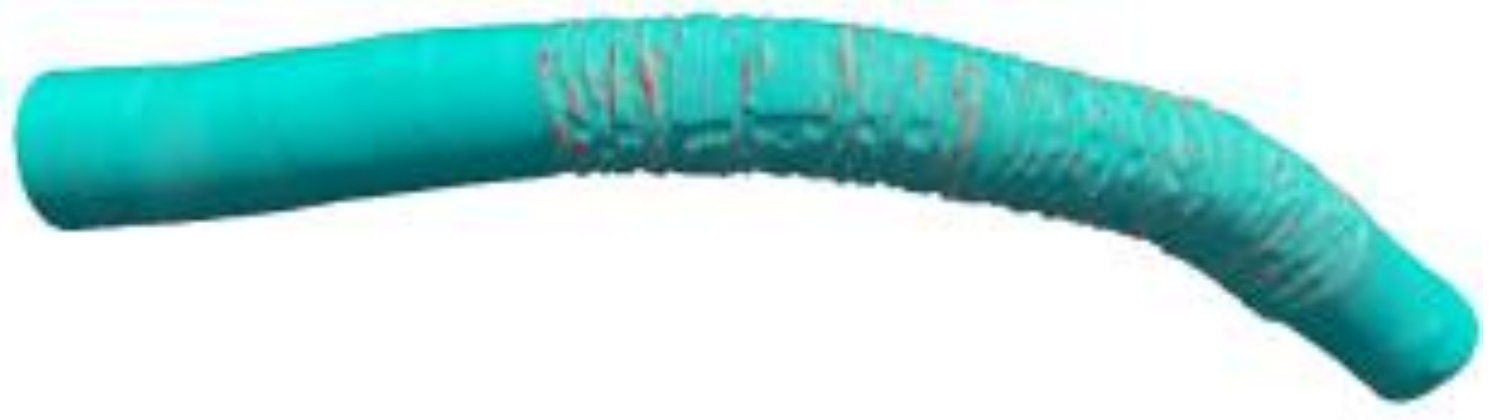

Figure 4. Recirculation zones(red) were quantified based on the ESS and the centerline direction (proximal $\rightarrow$ distal). The red areas in the luminal surface are where the vectors of the ESS are pointing opposite (more than 90-degrees away from) the proximal-to-distal direction along the centerline. 


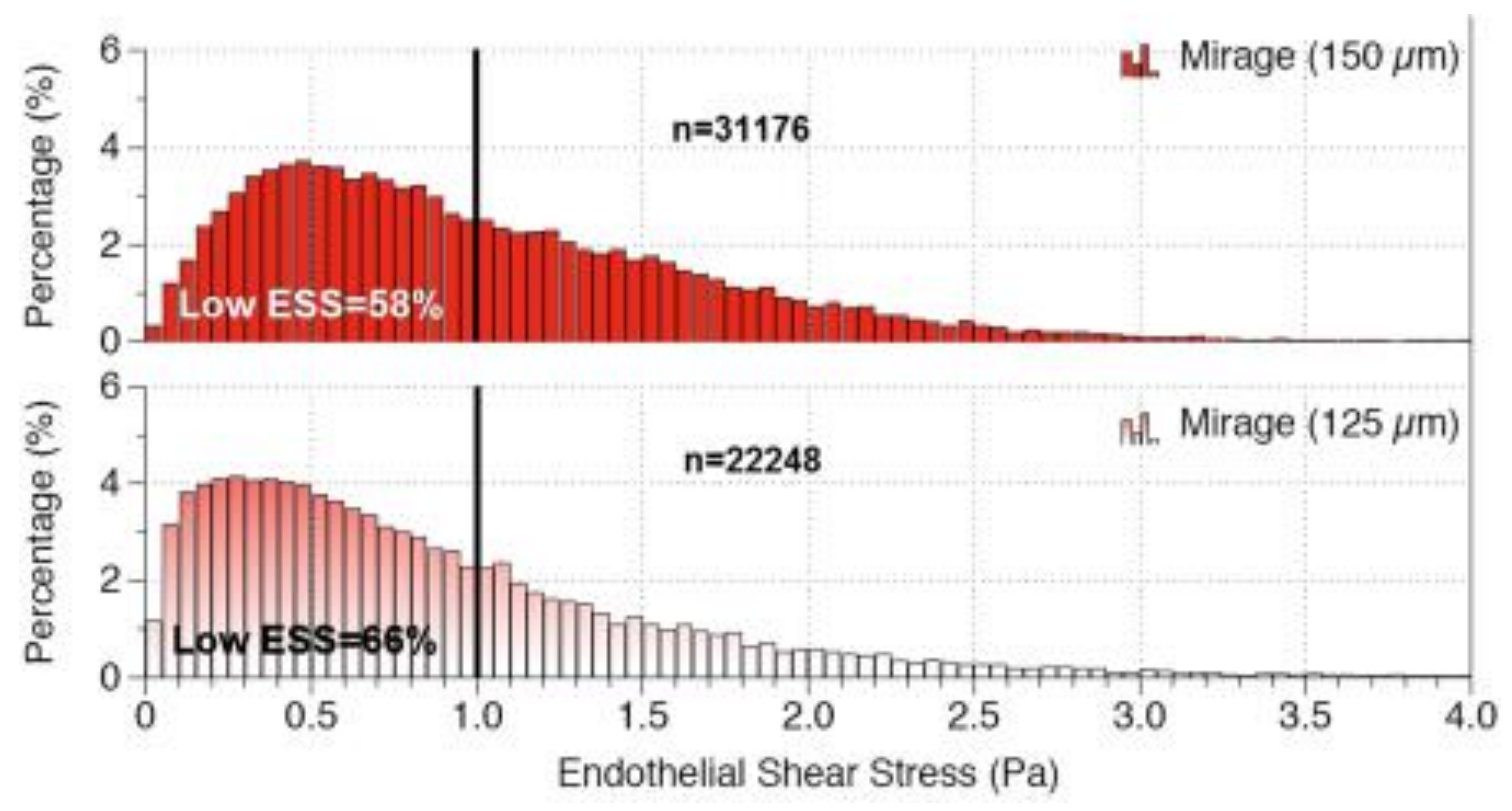

Figure 5. Histograms of ESS in scaffolded segments in scaffold groups. " $n$ " denotes the number of total ESS estimations at $5^{\circ}$-sectorial level.
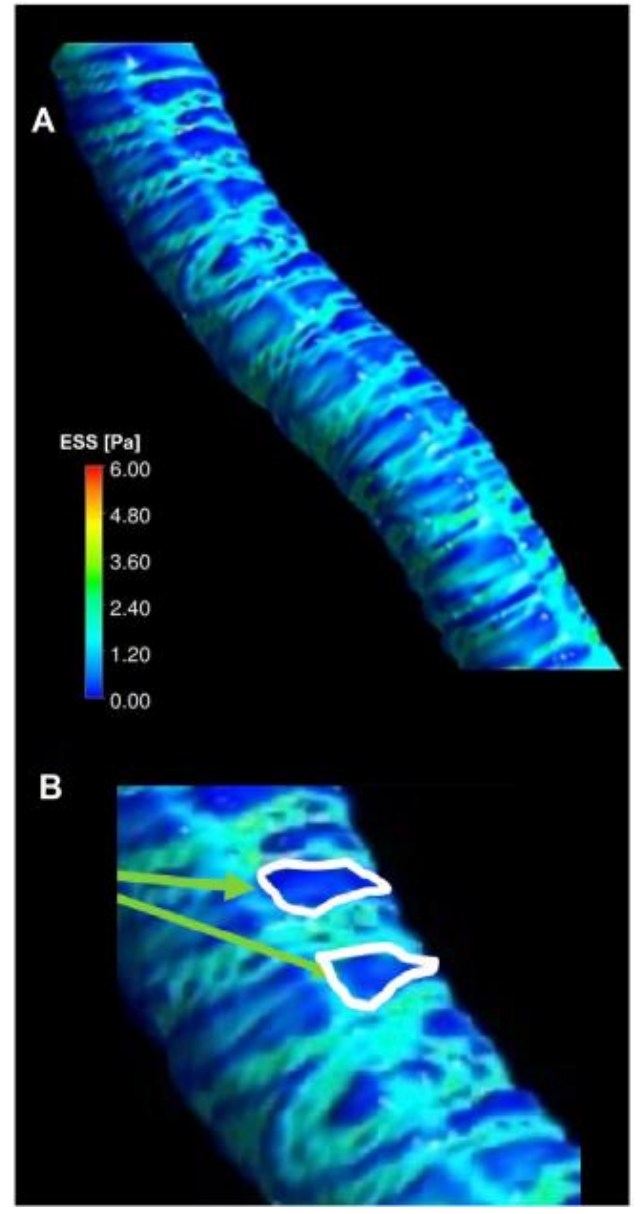

Figure 6. Three-dimensional reconstruction of scaffolded coronary anatomy from the fusion of coronary angiograms and OCT data with the local ESS being portrayed in a color-coded map (dark blue indicates low ESS $<1.0 \mathrm{~Pa}$ and aquamarine an ESS $\geq 1.0 \mathrm{~Pa}$ ) for Mirage scaffold ( $\mathrm{A}$ and $\mathrm{B}$ ). 
Supplementary Table 1: The median ESS and lumen area in OCT in scaffolded and non-scaffolded segment in OCT for each scaffold. The data are tabulated according to the ranking of ESS in Mirage bioresorbable scaffold.

\begin{tabular}{|c|c|c|c|c|c|}
\hline Scaffold & Animal & $\begin{array}{c}\text { Median ESS (Q1-Q3)- } \\
\text { Scaffolded segment } \\
(\mathrm{Pa}) \\
\end{array}$ & $\begin{array}{l}\text { Median Lumen Area (Q1-Q3)- } \\
\text { Scaffolded segment ( } \mathrm{mm}^{2} \text { ) }\end{array}$ & $\begin{array}{c}\text { Median Lumen area (Q1-Q3)- } \\
\text { Distal non-scaffolded segment } \\
\left(\mathrm{mm}^{2}\right)\end{array}$ & $\begin{array}{c}\text { Median Lumen area (Q1-Q3) } \\
\text { Proximal non-scaffolded } \\
\text { segment }\left(\mathrm{mm}^{2}\right)\end{array}$ \\
\hline MMSES-1 $(125 \mu \mathrm{m})$ & $E$ & $0.48(0.27-0.76)$ & $7.02(6.88-7.11)$ & $4.37(4.26-4.47)$ & 4.58 (4.21-4.72) \\
\hline MMSES-2 $(125 \mu \mathrm{m})$ & $\mathrm{F}$ & $0.48(0.24-0.87)$ & $8.98(8.29-9.81)$ & 7.40 (4.59-7.95) & $5.75(5.59-6.12)$ \\
\hline MMSES-3 $(150 \mu \mathrm{m})$ & $\mathrm{D}$ & $0.56(0.35-0.86)$ & $10.94(10.56-11.45)$ & $6.90(6.21-7.46)$ & $7.67(6.38-8.77)$ \\
\hline MMSES-4 $(150 \mu \mathrm{m})$ & D & $0.62(0.29-1.04)$ & $5.78(5.66-5.92)$ & $5.14(4.50-5.69)$ & $5.79(3.94-8.52)$ \\
\hline MMSES-5 $(125 \mu \mathrm{m})$ & $E$ & $0.63(0.35-1.04)$ & $11.21(10.92-11.40)$ & $8.71(8.25-9.14)$ & $6.14(5.06-7.91)$ \\
\hline MMSES-6 $(150 \mu \mathrm{m})$ & C & $0.92(0.56-1.35)$ & 12.59 (12.49-12.74) & $10.94(10.33-11.48)$ & $9.84(9.49-10.81)$ \\
\hline MMSES-7 $(150 \mu \mathrm{m})$ & G & $0.94(0.52-1.51)$ & $7.13(7.08-7.35)$ & $7.80(7.42-7.95)$ & $5.58(5.45-5.81)$ \\
\hline MMSES-8 $(125 \mu \mathrm{m})$ & $A$ & $0.94(0.53-1.56)$ & 7.25 (7.04-7.78) & $4.57(4.39-7.05)$ & $5.18(4.74-5.44)$ \\
\hline MMSES-9 (125 $\mu \mathrm{m})$ & $\mathrm{F}$ & $0.96(0.50-1.60)$ & $10.87(10.68-11.21)$ & $7.25(7.02-7.50)$ & 7.67 (7.42-9.09) \\
\hline MMSES-10 $(150 \mu \mathrm{m})$ & $B$ & $1.00(0.67-1.39)$ & $9.74(9.44-10.18)$ & $6.34(6.18-6.98)$ & $7.59(7.22-7.52)$ \\
\hline MMSES-11 $(150 \mu \mathrm{m})$ & A & $1.44(0.86-1.86)$ & $10.47(10.13-10.95)$ & $6.29(4.60-7.85)$ & $8.78(8.56-9.20)$ \\
\hline
\end{tabular}



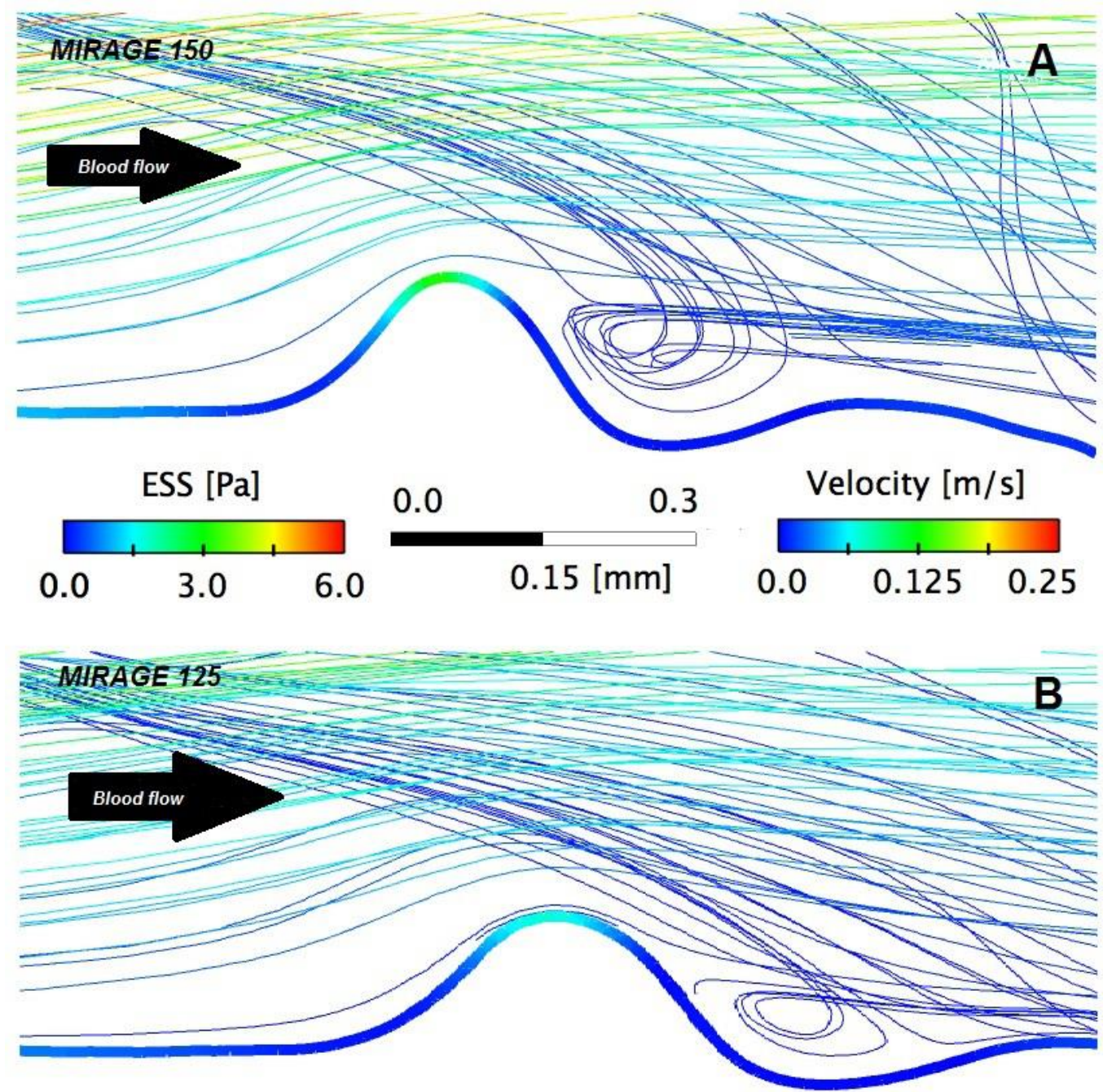

Supplementary Figure 1. Flow streamlines and associated ESS for representative cases of Mirage $(150 \mu \mathrm{m})$ and Mirage $(125 \mu \mathrm{m})$. 